Orbis Tertius, vol. XXIII, $\mathrm{n}^{\circ}$ 28, e088, diciembre 2018. ISSN 1851-7811

Universidad Nacional de La Plata

Facultad de Humanidades y Ciencias de la Educación

Centro de Estudios de Teoría y Crítica Literaria

\title{
Dos perspectivas latinoamericanas sobre el mundo ibérico. España contemporánea de Rubén Darío, y Portugal d'agora de João do Rio
}

\section{Lucía González*}

* Universidad Nacional de La Plata, Argentina

Cita sugerida: González, L. (2018). Dos perspectivas latinoamericanas sobre el mundo ibérico. España contemporánea de Rubén Darío, y Portugal d'agora de João do Rio. Orbis Tertius, 23(28), e088. https:// doi.org/10.24215/18517811e088 


\title{
Dos perspectivas latinoamericanas sobre el mundo ibérico. España contemporánea de Rubén Darío, y Portugal d'agora de João do Rio \\ por Lucía González \\ (Universidad Nacional de La Plata)
}

\begin{abstract}
Resumen:
Rubén Dario viaja a España en 1898 como enviado de La Nación de Buenos Aires y como fruto de ese viaje publica luego de dos años el libro España contemporánea. Unos años más tarde y desde Brasil, el escritor carioca João do Rio viaja a Portugal y escribe un conjunto de crónicas que luego publicará -en 1911- bajo el título Portugal d'agora. Los dos escritores citados se dirigen hacia paises -España y Portugal-que connotaban el margen económico y cultural dentro de Europa. En este sentido, el presente articulo pretende establecer un análisis comparativo y contrastivo entre dichos relatos de viaje con el fin de dilucidar las contradicciones que ambos discursos presentan frente a la modernidad cultural.
\end{abstract}

Palabras clave: Rubén Dario - João do Rio - modernización-viaje.

\section{Abstract:}

Rubén Dario travels to Spain in 1908 as a special correspondent for La Nación de Buenos Aires, and as a result of that journey he publishes, after two years, the book España contemporánea. Some years later, the carioca writer João do Rio travels from Brazil to Portugal and writes a set of articles that he will publish, in 1911, under the title Portugal d'agora. The two cited writers go towards countries -Spain and Portugal-which represented the economic and cultural margins in Europe. Thus, this article aims at establishing a comparative and contrastive analysis between these travel narratives with the aim of explaining the contradictions that both discourses present in comparison to cultural modernity.

KEYWORDS: Rubén Dario - João do Rio - modernization - journey.

El presente trabajo se propone analizar comparativamente los libros España contemporánea, publicado en 1900 por Rubén Darío, y Portugal d'agora, publicado en 1911 por el escritor brasileño João do Rio. Ambos libros son el resultado de los respectivos viajes de estos escritores hacia España y Portugal en el momento en el que dichas naciones se encontraban en crisis -tanto económica como social-, y permiten observar ciertos puntos de encuentro entre el decadentismo brasileño y el modernismo hispanoamericano, especialmente con respecto a las contradicciones que asumen estos discursos frente a la modernización económica y a la modernidad cultural que estaba atravesando América Latina a comienzos del siglo XX.

Las crónicas presentes en ambos libros procesan esas contradicciones a partir de una mirada valorizadora de la tradición. El reconocimiento del mundo ibérico resulta un componente clave del antipositivismo noventayochista de estos autores. El posicionamiento como latinoamericanos los autoriza a tomar una distancia prudencial para observar los conflictos políticos y sociales de los países que visitan y, al mismo tiempo, establecer un campo de identidad común entre sus países de origen y aquellos de los cuales fueron anteriormente colonia.

\section{APreciaciones EN EL MAR}

Las crónicas que forman parte de España contemporánea y de Portugal d'agora fueron producidas en un primer momento con el objetivo de ser publicadas en la prensa periódica, para La Nación de Buenos Aires en el caso de Rubén Darío, y para la Gazeta de Notícias de Río de Janeiro en el caso de João do Rio. Tanto uno como otro escritor son enviados como corresponsales a Europa para dar cuenta de la realidad social y política de las respectivas naciones ibéricas: Darío viaja en diciembre de 1898 con la premisa de realizar 
apreciaciones sobre la reacción española ante el "Desastre", y Do Rio realiza dos viajes -uno en 1908 y el siguiente en 1910 - con motivo de informar al público brasileño y a la gran comunidad portuguesa instalada en Brasil sobre la realidad política de Portugal. Ahora bien, dicha inscripción en la producción periodística da cuenta de la relevancia del vínculo entre periodismo y literatura en el período de entresiglos, y con ello, de la configuración de la crónica como espacio en el cual el escritor se distancia prudentemente de la escritura "mercantil" del periodismo y, al mismo tiempo, de los aparatos exclusivos y tradicionales de la república de las letras, estableciendo así un lugar de enunciación propio (Ramos 1989). Si bien, como señala Susana Zanetti para el caso de España contemporánea, la publicación en formato libro conlleva una intención discursiva orientada hacia el ensayo más que a la crónica, hay que tener en cuenta las condiciones materiales en las cuales se originan estos textos, ya que si se piensa, junto con Julio Ramos, que la funcionalidad de la crónica latinoamericana de entresiglos es representar y reordenar un nuevo espacio urbano altamente transformado, el destino al cual se dirige cada uno de estos autores (es decir, España y Portugal) cobra una singularidad mayor.

No sólo la ciudad se diagrama, para el escritor cronista, en función de "centros" y "márgenes”, sino que el mundo entero se presenta ante él como un sitio en el cual se destacan nuevas economías y culturas poderosas, generando la marginalización de otras. Es así como España y Portugal, a fines del siglo XIX, connotan el margen de Europa por tratarse de dos antiguos imperios en decadencia: tanto la pérdida de Cuba en 1898 por parte de los españoles, en manos de los norteamericanos, como el desgaste de la monarquía portuguesa, que desde hacía tiempo cedía su poder imperial ante otras potencias como Inglaterra, se perciben como pruebas que contradicen el "progreso" implícito en el proceso modernizador y en el discurso positivista que lo sostiene ideológicamente.

Ahora bien, además de considerar algunas de las condiciones sociales de producción de ambos volúmenes, importa pensar el tipo de figuraciones culturales que establecen estos dos escritores con respecto al lugar al que se dirigen y con respecto a sí mismos en tanto viajeros.

Un elemento interesante para considerar comparativamente ambos relatos de viaje se refiere al modo diverso en que los sujetos de enunciación construyen, en sus textos, una autoidentificación de sí mismos como cosmopolitas. En el caso de España contemporánea, el escritor hace referencia a la vida de a bordo, centrándose en dos escenas paradigmáticas: el encuentro con un presidiario italiano que vuelve a su país para ser juzgado por un crimen, y el recuerdo de un náufrago norteamericano, conocido en otro viaje previo. Darío es capaz de reordenar la experiencia vivida en el barco y de apropiarse de lo que ésta le ofrece para armar discursivamente el camino simbólico hacia España, observando sin perturbaciones la "máquina social en miniatura" que es el transatlántico en donde se encuentra, "un lindo laboratorio de psicología, en donde se hace obligatorio el comercio de la conversación" (Darío 1987: 2). Configurándose como un "cosmopolita extremo", es decir, como aquel que es lo suficientemente dúctil como para entablar diálogo con todos y en cualquier situación, Darío es altamente competente para entrar en ese tipo de comercio e, incluso, para hablar con aquellos que viajan en tercera clase, como por ejemplo con un prisionero italiano, permitiéndole desplegar así una aproximación "etnográfica" hacia el otro. ${ }^{1}$ Haciendo uso de sus capacidades, Darío consigue que el italiano (el primer individuo que focaliza en su relato) comparta con él los motivos de su retorno a Italia y los pormenores de su acusación, dejando al descubierto un crimen por causas materiales. Esto decepciona al escritor nicaragüense, que inicialmente había idealizado al personaje considerándolo como un inocente, creyendo que el delito había sido cometido por causas sentimentales, como "vendetta". La decepción (que es también una pose frente al lectorado) resulta de la puesta en cuestión, a través de ese caso, del estereotipo del espíritu italiano, fundado en la pasión, pero en todo caso permite reforzar la identidad narcisista de un "yo" centrado en la valoración estética de las pasiones en desmedro del mundo material, elemento clave en el espiritualismo contemporáneo que el propio Darío encarna y despliega.

Esta imagen de la corrupción de ciertos valores "espirituales", propios de la latinidad (según la concepción que consolida el ensayo Ariel de José E. Rodó, editado en 1900), dialoga con el modo en el que Darío 
representa al segundo individuo, evocado a partir del recuerdo de un viaje anterior, en un traslado de Cuba a Santander, en España. En ese trayecto, el transatlántico se había encontrado con un náufrago estadounidense (un trabajador de una fábrica de jabones norteamericana) que se negó a ser rescatado. Ahora, reviviendo ese recuerdo en la "soledad oceánica" de ese mar que es como un "ondulado desierto", Darío evoca al náufrago como "el Colón yankee que va a descubrir España" (Darío 1987: 5). Esta imagen insiste en reforzar la inscripción de su viaje a España en el seno de las polarizaciones cristalizadas poco después en el Ariel.

Mientras el escritor nicaragüense ostenta su cosmopolitismo extremo a través de la ductilidad con que se mueve entre los diversos polos sociales del barco, João do Rio da cuenta, desde el comienzo de Portugal d'agora, de la falta de las competencias propias de un hombre cosmopolita, manifestando su preocupación e interés por ser un "homem que viaja", categoría que define como "a função natural do homem cosmopolita, civilizado e superior" (Do Rio 1911: 7). Como él nunca antes ha viajado, la ida a Portugal se convierte entonces en un viaje de iniciación. Su primera crónica, que llamativamente se titula "No mar" -es decir, "En el mar"-, repitiendo el título elegido por Darío para abrir su España contemporánea, se organiza en torno a la figura del escritor y a los sufrimientos por los que ha pasado al demorarse tanto en lograr subir a un transatlántico: "O homem que não viaja é um desprezado, um desclassificado" (Do Rio 1911: 5). El viajar se ha convertido, según Do Rio, en una actividad necesaria para el hombre moderno: "Como resistir à corrente colosal? Como não ser do século e não desejar viajar, ver novo, lavar a alma, lavar o cérebro, lavar os sentimentos, colaborar na grande obra de synthese universal [...]?" (Do Rio 1911: 10). De este modo, deja en claro que los nuevos tiempos imponen la necesidad de llevar a cabo nuevas actividades y de establecer nuevas relaciones.

Ahora bien, el mero hecho de viajar no alcanza para adquirir el anhelado cosmopolitismo moderno. Como Darío, también el escritor brasileño entabla conversación con el resto de los pasajeros. Sin embargo, lejos del éxito que obtiene el nicaragüense, Do Rio se siente abrumado por la excesiva confianza entre los pasajeros y, apabullado, decide huir y encerrarse en la sala de máquinas.

En este caso, retomando la comparación con las escenas analizadas de España contemporánea, Do Rio fracasa en el "negocio" de la conversación, como si su capital simbólico fuese escaso como para dominar la situación e imponerse como un cronista eficazmente inquisidor de otros mundos sociales. Es decir, no actúa como un cosmopolita extremo, capaz de moverse por cualquier sitio como si fuese el suyo, sino como un cosmopolita improvisado que aún no ha adquirido las capacidades suficientes como para adaptarse a cualquier tipo de encuentro. Es probable que su fuerte enraizamiento local, su origen de clase (no oligárquico), su condición de mulato y de homosexual, e incluso el carácter más bien epigonal de su escritura decadentista (respecto de la centralidad enorme de Darío en el seno del modernismo hispanoamericano), entre otros factores, se traduzcan discursivamente en esta inseguridad con que Do Rio asume su propio cosmopolitismo recién adquirido, más periférico (más provinciano) que el que ostenta Darío desde el inicio de su viaje. Mientras Darío es "naturalmente" cosmopolita, Do Rio se esfuerza por serlo, forzando sus propios límites, de una manera doblemente impostada (considerando que ese dandismo cosmopolita ya es en sí mismo una "pose" en el sentido en que la considera Molloy [2012]).

Ahora bien, el modo diverso en que Darío y Do Rio se posicionan como viajeros es fundamental para entender el modo en que cada uno configura su llegada a España y a Portugal. Mientras el escritor nicaragüense no necesita llegar a su destino para marcar las pautas de su identificación con el mismo, el cronista carioca, por el contrario, precisa ansiosamente visualizar el lugar para poder reconocerse en él. Con sus diferencias, entonces, ambos diagraman imágenes que funcionan como puentes, lazos de unión entre España e Hispanoamérica, y entre Portugal y Brasil. Al comienzo del libro, Darío determina una cadena de continuidades entre el punto de origen y el punto de llegada: 
Siento que estoy en una casa propia, voy a España en una nave latina, a mi lado el sí suena. Sopla un aire grato que trae todavía el aire de la pampa. De nuevo en marcha y hacia el país maternal que el alma americana americanoespañola- ha de saludar siempre con respeto, ha de querer con cariño hondo. [...] Porque si ya no es la antigua, poderosa, la dominadora imperial, amarla el doble; y si está herida tender a ella mucho más (Darío 1987: 1).

Se presenta aquí, como apunta Colombi (2004), la construcción de un campo de identidad común entre el viajero y su objeto, desmontando el mecanismo de la confrontación que había caracterizado la retórica del viaje a España, plegándose de esta manera a un discurso emergente en la época que brega, en los dos lados del Atlántico, por la regeneración del vínculo entre América y España. En este sentido, es posible hablar de un "dispositivo hispanista" que, tal como señala Oscar Terán, responde, en esta etapa, tanto a la preocupación por la redefinición de una identidad nacional (que debe "inventar un linaje autóctono ante lo que se percibía como una amenaza de disolución contenida en el aluvión inmigratorio") como "al recelo hacia el avance del expansionismo yankee, alentando la elaboración de lo propio contrastante con la del hermano-enemigo del norte" (Terán 1992: 130).

En las líneas que dan inicio a ambos textos, el modo en que estos autores establecen su relación con el país ibérico es sintomático de lo que acontece en el resto del libro: en ambos, la unidad posible aparece en un linaje latino que, por sobre todas las cosas, da origen a una lengua en común, al mismo tiempo que la tradición cobra peso en la revisión de los elementos culturales compartidos: las corridas de toros, el carnaval y, por sobre todo, la actividad literaria. El trayecto que recorren está forjado por la selección de estas prácticas que permiten confirmar una identidad tradicional ibérica integradora.

España es definida por Darío como un yacimiento al que aún hay que explorar, como un suelo óptimo pero que precisa de desarrollo: "Hay que ir por el trabajo y la iniciación en las artes y empresas de la vida moderna" (Darío 1987: 76). Con este gesto, Darío potencia su lectura en clave espiritualista de la realidad social (en la medida en que el arte se convierte en el principio rector del progreso -entendido como progreso del espíritu- por encima del progreso material). A la vez, su propio espejamiento de sí mismo en los noventayochistas redunda en una fuerte legitimación del modernismo, erigido en el movimiento adecuado para desplegar ese progreso simbólico, por la vía del arte.

En el caso de Do Rio, el vínculo con Portugal se establece de modo diferente. Si en Darío, la fuerza unificadora entre España y América radica en la pertenencia a una misma cultura (lo cual se percibe desde el barco mismo, a tal punto que no es necesario pisar el suelo español para constatarlo), por el contrario Do Rio enfatiza la cercanía con la cultura lusitana a partir de la figura del locus amoenus:

E, de repente, como nas mágicas, sentia um sentimento até então insentido: o enternecimento diante da paisagem. [...] Diante a cidade a acordar, no Tejo largo e profundo, não era o pasmo que me acomettia, era o reconhecimento de me sentir ligado a uma raça valorosa e antiga [...]. Sentia bem forte um imenso aconchego amoroso, como se carregada de penas e de glorias, coberta de trophéos, maternalmente Lisboa abrisse a belleza deliciosa de seu amphiteatro numa acolhença cheia de penetrante ternura. E, por isso, tudo parecia tão suave, céo e terra, arvores do monte e aguas do rio, como se os trechos a descobrir na paisagem fossem novas acolhidas de meiguice na corrente crescente de encanto e de infinito bem estar (Do Rio 1911: 32; aquí y en todas las citas se respeta la ortografia de la primera edición).

A diferencia de Darío, el autor brasileño apela a una memoria emotiva que se activa a través del paisaje. Esta imagen idealizada del espacio, en la que circunscribe a Lisboa, reaparece cuando contempla la ciudad de lejos, desde el mar, en una mañana clara y soleada, repleta de aves, lo que contribuye a la configuración de un espacio idílico, impoluto y no corrompido por los cambios que el proceso modernizador introduce en las ciudades. El atraso portugués se convierte así en una ventaja, en una garantía de la preservación de la identidad cultural. De este modo, desde el comienzo se establece una contraposición entre la ciudad que conserva su convivencia armónica con el medio natural -y por extensión, con el pasado histórico-, y el medio urbano del hombre americano que proviene de un país "sem tradição, com os olhos no futuro, não vendo mais do que ascensores, confronto, estradas de ferro...” (Do Rio 1911:32). En estas citas, además de asociar la preservación del espacio físico a la preservación de las tradiciones, continúa presentándose como un viajero inexperto que mira Portugal "por primera vez", priorizando el énfasis en el paisaje. 
Al igual que Darío, también el escritor carioca está preocupado por mostrarle al público de su país el estado de desarrollo de la literatura ibérica y, al remitirse a la producción literaria y el teatro portugués en el presente, señala la escasa apertura de Portugal hacia otras culturas y hacia la novedad en el campo artístico. Sin embargo, desde su punto de vista, la falta de innovación no equivale a "decadencia", ya que logra destacar a varias figuras. Para Do Rio, el encierro artístico depende de las condiciones geográficas y económicas del país: "Portugal é de costumes resistentes como todo paiz de fondo rural" (Do Rio 1911: 118), despejando así la sombra de la crisis política por sobre el arte. Si bien la situación de inestabilidad social es comentada a través del registro que el cronista hace con respecto al medio periodístico y a su producción, contrapone a esa inestabilidad el desarrollo de un arte ibérico libre de esos avatares, en una operación próxima a la de Darío, por la cual la crisis socioeconómica es superada por la vía rectora de la espiritualidad.

\section{LAS CIUDADES}

España contemporánea y Portugal d'agora no solo se inician con una crónica que lleva el mismo título, sino que además ambos textos privilegian el recorrido por dos ciudades, dando cuenta -cada uno con su modalidad particular- del modo en que el espacio urbano es el escenario por antonomasia en donde se intensifican las características de la modernidad y, a su vez, se visualizan sus contradicciones. ${ }^{2}$ En el caso de Darío, el relato sobre la modernidad de España se centra en Barcelona y en Madrid, y en el caso del escritor carioca, en Lisboa y luego en Porto. Dicha elección parece radicar en el mismo objetivo: por un lado, describir ciudades donde la modernización se vuelve más tangible y, por otro, dar a conocer al lectorado otro centro urbano en donde las prácticas tradicionales - culturales y económicas- aún son dominantes, conformando así un binomio capaz de dar cuenta de la inserción problemática y dispar de un país periférico en el seno de la modernización europea. Gracias al arribo a puertos importantes, ambos cronistas dan inicio a su recorrido a partir de la ciudad más moderna.

En el caso de España contemporánea, Rubén Darío escoge entrar al país desde Barcelona para luego continuar por Madrid. Como en el libro del escritor carioca, el mundo ibérico se observa desde Latinoamérica. Ahora bien, las referencias que se hacen a Buenos Aires no remiten a una ciudad sin historia; no hablan de una modernidad vacía: al contrario, dan cuenta de una modernidad cultural en auge que Darío se empeña en resaltar. La capital argentina resulta un punto referencial para los lectores de La Nación a la hora de cotejar cuáles son efectivamente las novedades de Barcelona - por ejemplo, al señalar que el café Colón, con las discusiones políticas y culturales que allí se realizan, no se distancia demasiado de lo que sucede en las cafeterías de Buenos Aires-, así como también para demostrar la distancia abismal que separa las prácticas culturales porteñas respecto de las formas anacrónicas que se registran en Madrid. Buenos Aires es la ciudad moderna que permite observar la cultura de España como algo ya conocido e incluso superado. Darío, en este caso, elige ampararse en un "nosotros" que no sólo le sirve como estrategia para acercarse al lectorado de La Nación, sino que además le permite analizar la realidad ibérica desde la ciudad más moderna de América Latina.

Si bien Darío le dedica pocas páginas a Barcelona -considerablemente menos que a Madrid-, le alcanzan para resaltar el desarrollo de esta metrópoli, sobre todo en lo que se refiere a lo cultural y a lo político. Entrar discursivamente al país ibérico por esta ciudad implica una elección por parte del cronista, la cual, junto con las referencias realizadas sobre la "herida España" en la crónica "En el mar", colabora para definir su posicionamiento antes de ingresar a la capital española. Si, como se analizó más arriba, Darío promulga un retorno al país en lazo con la conservación del alma "americanoespañola", amenazada ante la inminencia del capitalismo imperante en Estados Unidos, la valoración de la modernidad de Barcelona -y el acercamiento que formula entre ésta y Buenos Aires- establecen una distancia desde la cual el cronista observará Madrid: 
Desde luego sé que en Madrid me encontraré en otra atmósfera, que si aquí existe un afrancesamiento que detona, ello ha entrado por una ventana abierta a la luz universal, lo cual sin duda alguna, vale más que encerrarse entre cuatro muros y vivir el olor de cosas viejas (Darío 1987: 19).

Ahora bien, Rodrigo Caresani propone una lectura de la errancia dariana por el espacio urbano que invita a repensar el concepto de "viajero importador" propuesto por Julio Ramos -en tanto mero transmisor de modelos culturales modernos, para un público latinoamericano ávido del consumo de lo "novedoso"-, al señalar que, en Darío, la narrativización de la experiencia en fuga y desencontrada, vivenciada en las grandes metrópolis de fines del novecientos, se efectúa a partir de la configuración recurrente de "paisajes de cultura". De este modo, en las crónicas del escritor nicaragüense, las ciudades se recorren y observan a partir de un repertorio exhaustivo de referencias a poetas, artistas y demás aspectos culturales que "afirman la convicción dariana de que el entorno urbano se puede aprehender, descifrar e incluso controlar como un paisaje de citas" (Caresani 2014: 175). De este modo, el viajero toma un rol activo y muy poco neutral respeto de lo que observa y selecciona para transmitir a su público: sus ciudades son ciudades del arte, espejos para la confirmación de los valores de su cultura estética.

En el caso de Madrid, además de la revisión de ciertas prácticas tradicionales, prevalecen las crónicas en las que el escritor comenta aquellos aspectos requeridos para alcanzar los mandatos de una modernidad artística: concurre a una exhibición de arte (evento moderno por excelencia); revisa la situación de la prensa periódica, y el estado actual de la prosa y de la poesía española y, al mismo tiempo, indaga en la edición de revistas y el desarrollo de la caricatura. Darío circula por esos ámbitos como un lector privilegiado, pero además se comporta como un crítico del arte y de la literatura.

El resto de las aristas del campo cultural se observan del mismo modo que se miran las pinturas en una exhibición: desde la distancia que permite una indagación aguda y crítica. Solo que, en este caso, es el propio cronista el que muestra las obras, como si éstas fuesen parte de una exhibición mayor. Dicha distancia, en Darío, está dada por la condición de modernidad que el mismo escritor le adjudica al arte y a la cultura en América Latina, la cual le permite registrar los rasgos ya caducos de las prácticas artísticas de España. A su vez, la periferia cosmopolita, de la cual proviene, le permite distanciarse de la modernidad parisina y reconocer, en la tradición española, un reservorio más que valorable para la creación artística:

Y comprendí el alma de la España que no perece, la España reina de vida, emperatriz del amor, de la alegría y de la crueldad; la España que ha de tener siempre conquistadores y poetas, pintores y toreros.

¡Castillos en España! Dicen los franceses. Cierto: castillos en la tierra y en el aire, llenos de leyenda, de historia, de música, de perfume, de bizarría, de color, de oro, de sangre, de hierro, para que Hugo venga y encuentre en ellos todo lo que haga falta para labrar una montaña de poesía; castillos en que vive Carmen y se hospeda Esmeralda, y en donde los Gautier, los Musset y los artistas todos de la tierra pueden abrevarse de los embriagadores vinos del arte. Y en cuanto a vos, don Alonso Quijano el Bueno, ya sabéis que siempre estaré de vuestro lado (Darío, 1987: 124).

Si bien esta distancia le facilita vislumbrar una posibilidad prometedora para el arte español, no le impide al mismo tiempo revisar de manera crítica ciertos preconceptos que los españoles formulan sobre los latinoamericanos, como por ejemplo el uso de un español "impuro" y degradante, o la inclinación "demasiado marcada" de los escritores argentinos hacia las literaturas extranjeras: "Por lo general, aquí se compara lo propio con lo extranjero, cuando no con aire de superioridad, con un convencido gesto de igualdad. No se dan cuenta de su estado actual" (Darío, 1987: 220). Como se ve, la mirada crítica sobre ese presente no solo está direccionada a evaluar la situación española, sino que también orienta los propósitos discursivos hacia el reconocimiento del arte y la literatura latinoamericanos, en tanto les corresponde un lugar de privilegio y de superación respecto del desarrollo cultural español.

También Do Rio comienza su recorrido por la ciudad más moderna. En el retrato que el cronista establece de Lisboa, son reiteradas las imágenes -además de la inicial- en las que el trayecto por el lugar se enmarca en mañanas y tardes luminosas y pacíficas, lo cual colabora en la configuración de la capital de Portugal como el locus amoenus instaurado desde el comienzo. Es importante destacar que esta imagen idealizada se construye 
a partir de un contrapunto con la ciudad de la que proviene el cronista, Río de Janeiro, cuya gravitación es tan fuerte que define el seudónimo literario de este escritor. Es posible encontrar diferenciaciones entre Río de Janeiro y Lisboa, a medida que el autor avanza en su recorrido por la ciudad peninsular. Cuando Do Rio se interna en las calles de Lisboa para recorrerla de noche, la distancia desde la cual la observa se acorta hasta obtener una visión más profunda y compleja de sus habitantes. El cronista se encuentra con un panorama que aprehende mediante el uso constante del término "gozo", ya que los ciudadanos -de todas las clases sociales- habitan ese espacio en provecho de un placer personal, fundado por ejemplo en el disfrute del teatro. Al caracterizar esa vida nocturna, compara Lisboa con el mundo carioca, señalando los consumos diferentes: en Río de Janeiro todo se hace a una velocidad exacerbada, importando más el hecho de consumir que el de disfrutar de aquello que se adquiere. La diferencia también radica en que todas las clases sociales conviven en la vida cultural nocturna, rasgo que Río de Janeiro ha perdido, al apropiarse de ciertos espacios exclusivamente para las clases acomodadas. Sin embargo, la imagen de Lisboa no demora en complejizarse a partir de la emergencia de la realidad social y política:

Entretanto, nessa alegria civilizada, para os que pretendem ver mais do que a apparencia, Lisboa é uma cidade corroída de scepticismo, á procura de uma solução para os arranques de certas cóleras que lhe enfeiam a graça sybarita. As cóleras não podem ser reprimidas nas almas mais scepticas, principalmente porque o scepticismo, vindo da descrença geral, á forçado a acreditar na violência dos impostos, na brutalidade da policia no páo de sebo angustioso de uma politica de partidos, estafada e gasta (Do Rio 1911: 59).

A través de un acercamiento al modo en que los lisboetas experimentan la vida urbana, surgen nuevas facetas de esa ciudad que, si bien no revierten su representación como locus amoenus, al menos la matizan.

Luego de visitar la capital portuguesa, el cronista se dirige hacia Porto, la segunda ciudad más grande de Portugal, que se distingue sustancialmente respecto de Lisboa por la vitalidad con que allí se mantienen las costumbres asociadas a la vida rural. Porto es entonces el sitio en donde, para el cronista, es posible reconocer, aún vivo, el pasado portugués que dio origen a Brasil:

O Porto é uma cidade integralmente diversa de Lisboa em usos, aspectos, costumes, mas inmensamente parecida com o Rio antigo. Basta lá passar uma semana para ser ter certeza de que foi a gente do norte de Portugal que formou as nossas cidades e que ainda hoje fornece ao nosso movimento maior contingente (Do Rio 1911: 236).

Así, Do Rio construye una visión de Lisboa y de Porto marcada por la experiencia de la modernidad periférica carioca. El acento en el vínculo de afiliación entre Brasil y Portugal implica un desplazamiento relativamente innovador respecto de la centralidad de París, dominante entre los letrados de entresiglos. Si, tal como señala José Luis Romero (2001), las transformaciones arquitectónicas de entresiglos no logran hacer desaparecer por completo la "vieja ciudad" (sino que ésta actúa como un "fantasma" que demuestra la superposición de épocas), Porto funciona para el escritor brasileño como una imagen latente, residual, fantasmática (pero en sentido positivo) respecto del pasado de Brasil, cuya vigencia es preciso reconocer, para resistir, desde la memoria, el arrasamiento vertiginoso de las identidades colectivas llevado a cabo por la modernidad.

Luego de la visita a Porto, y preparándose para abandonar también Lisboa, Do Rio cierra su libro de modo prescriptivo, al afirmar que las relaciones entre Brasil y Portugal deben afianzarse en pos de la continuidad de una identidad cultural compartida:

Ao deixar Portugal, como resumo de variadissimas impressões, impressões cheias de crença no futuro do pequeno paiz de bondade e belleza, vivia no meu espirito o problema da absoluta necessidade de uma verdadeira aproximação das duas nações que tem a conservar o patrimônio de uma língua esplendida... (Do Rio 1911: 282).

Señalando los puntos de interés en relación al vínculo luso-brasileño, Do Rio enumera medidas económicas -como la necesidad de un tratado comercial entre los dos países-, pero también propone medidas culturales tendientes a religar Brasil y Portugal, fundamentalmente “...estudar a maneira de se fundar em qualquer 
das duas capitães, ou simultaneamente em ambas, uma revista que seja o órgão para servir de interprete permanente a este movimento de aproximação luso-brasileira" (Do Rio 1911: 291). En este sentido, pergeña un medio editorial transnacional que afirme los lazos entre ambos campos intelectuales, en un movimiento próximo al que despliegan otros latinoamericanos vinculados al modernismo estético (en este caso, en París) como Leopoldo Lugones o Manuel Ugarte. Es interesante pensar que, en este discurso prospectivo, que se propone vislumbrar un futuro para ambas patrias, Do Rio se piensa a sí mismo como un sujeto protagónico, sobre todo si se tiene en cuenta la realización de la prerrogativa de integración cultural, gracias a la creación, años después, de la revista Atlântida, impresa en Portugal entre 1915 y 1920, y dirigida por el propio Do Rio desde Brasil y por el poeta João de Barros desde Portugal. ${ }^{3}$

Se puede agregar, que en la escritura de España contemporánea y de Portugal d'agora, los modos de escribir la tradición y de asumir la dicotomía entre lo local y lo cosmopolita están atravesados por formas y grados de autolegitimación letrada diferentes: Darío, consolidado en su liderazgo del modernismo continental, embandera la reivindicación de una literatura hispanoamericana que se quiere ligada a la tradición española pero no sometida a ella; do Rio, en cambio, se afirma más bien como un carioca en viaje de descubrimiento inaugural de la madre patria. ${ }^{4}$ El sitio que cada uno se asigna para sí frente al país ibérico -en tanto hispanoamericano para Darío, y en tanto brasileño para el caso del escritor carioca-implica la configuración de formas de mediación cultural diversas. Frente al cosmopolita radical que es Darío, do Rio -cosmopolita improvisado- parece más atado a la lucha por su autolegitimación en el más acotado espacio cultural carioca.

\section{CoDA: Do RIO EN TIERRAS DEL MODERNISMO HISPANOAMERICANO}

En 1915, poco después de la edición de Portugal d'agora, Do Rio vuelve a viajar, pero en esta ocasión se dirige a Buenos Aires, un enclave central del modernismo dariano. Allí permanece una semana, escribiendo, para la Gazeta de Notícias de Río de Janeiro, algunas crónicas en las que reflexiona sobre su visita al país vecino. En total, bajo el título "Viagem a Buenos Aires", se editan seis notas desde el 30 de abril hasta el 6 de mayo de ese año, fecha en que el escritor vuelve a Brasil. ${ }^{5}$

En la primera crónica de esta serie, Do Rio se esfuerza, una vez más, por expandir su cosmopolitismo, venciendo algunos límites provincianos y nacionalistas:

Eu desejaria ter o espirito da Sul-americana para ligar estas frases, para que estas frases exprimissem uma tendência. Não devo estar em Buenos Aires como um estrangeiro. Devo estar como americano que deseja compreender na muda revelação da cidade um dos condutores do futuro sul-americano (Do Rio 1915, cursiva nuestra).

Con estas líneas, Do Rio establece las pautas fundamentales de su discurso sobre la capital argentina. En primer lugar, el viaje para él no implica un desprendimiento de su país, sino un movimiento de expansión marcado por las continuidades. En segundo lugar, la ciudad continúa siendo el único espacio de interés, observada como promesa de desarrollo. Las transformaciones modernizadoras adquieren un cariz positivo, conformando un nuevo espacio, ya no acotado a Río de Janeiro o a Buenos Aires, sino inclusivo de toda Sudamérica. Las seis notas escritas en y sobre Buenos Aires apuntan en esta dirección: la capital argentina se explora procurando encontrar allí los rasgos de la ciudad sudamericana. Además, esta capital se distingue positivamente por tener gobernados sus aspectos salvajes en una "formidável domesticação do pampa", para volverse así una "Londres gaúcha" (Do Rio 1915). Y una vez más, las grandes ciudades europeas aparecen como un faro problemático: siendo símbolos de progreso para las ciudades americanas, estas últimas, en su intento de igualarlas, corren el riesgo de perder sus características identitarias. Por lo demás, estas observaciones de do Rio convergen con las del movimiento arquitectónico neocolonial que, por entonces, despunta en Buenos Aires, de la mano de varios intelectuales influidos por la sensibilidad modernista, como el ensayista Ricardo Rojas, el arquitecto Ángel Guido y su hermano, el artista plástico Alfredo Guido. 
Con el cotejo de estos dos viajes a Portugal y a Buenos Aires, también se vislumbra en do Rio la "expansión de la autoridad estética" (a la que se refiere Caresani [2014: 183]) propia de un viajero que se afirma a sí mismo para definir la identidad cultural. Ya sea reflexionando sobre la relación entre Brasil y Portugal, o entre Brasil y Argentina, el escritor carioca (al dar cuenta de la inserción problemática de los países latinoamericanos en el proceso modernizador) busca dilucidar los caminos mediante los cuales Brasil pueda modernizarse, pero conservando sus rasgos distintivos.

Lamentablemente, el viaje por Buenos Aires no pone a Do Rio en contacto directo con la figura de Darío (por entonces, de viaje en el exterior), pero su visita a Buenos Aires (una ciudad central para el desarrollo del modernismo hispanoamericano) aproxima necesariamente aun más la estética y la ideología del carioca respecto de la de este "Maestro". Sería imposible pensar a Do Río, ávido de alta cultura porteña, recorriendo las librerías y los cafés de Buenos Aires sin toparse con la estatura literaria del autor de Los raros. Además, teniendo en cuenta el vínculo que Raúl Antelo señala entre Do Rio y Enrique Gómez Carrillo, parece evidente en qué medida el carioca sigue de cerca las creaciones de este movimiento literario hispanoamericano. ${ }^{6}$ En esta dirección, podría conjeturarse que los diversos puntos de contacto arriba señalados, entre España contemporánea y Portugal d'agora, provienen no sólo de una convergencia abstracta entre las concepciones del viaje y de la escritura entre ambos autores, sino también de una apropiación y reelaboración de los modelos del modernismo hispanoamericano (incluso de los textos formulados por el propio Darío) por parte de un escritor periférico respecto del movimiento hispanoamericano, con un alcance más bien local (o en todo caso nacional), más inseguro respecto de sus credenciales simbólicas, y más ostensiblemente forzado a volverse un cosmopolita extremo, como poseur en segundo grado de la pose modernista.

\section{BIBLIOGRAFÍA}

Antelo, Raúl (1989). João do Rio. O dândi e a especulação, Rio de Janeiro, Timbre Taurus.

Caresani, Rodrigo Javier (2013). "Prólogo”, en Rubén Dario Crónicas viajeras: derroteros de una poética, Buenos Aires, EFF.

Caresani, Rodrigo Javier (2014). “Un camp americano? Errancias del sujeto en las crónicas de Rubén Dario” en Exlibris, año 3, $n^{\circ}$ 3, pp. 172-183.

Colombi, Beatriz (2004). Viaje intelectual. Migraciones y desplazamientos en América Latina (1880-1915), Rosario, Beatriz Viterbo.

Colombi, Beatriz (2010). "El viaje, de la práctica al género", en Mónica Marinone y Gabriela Tineo (Eds.). Viaje y relato en Latinoamérica (pp. 287-308), Buenos Aires, Katatay.

Darío, Rubén (1987). España contemporánea, Barcelona, Lumen.

D’Ávila, Cristiane (org.) (2013). Cartas de João do Rio a João de Barros e Carlos Malheiro Dias, Rio de Janeiro, Funarte.

Do Rio, João (1911). Portugal d’agora, Rio de Janeiro, Garnier.

Frisby, David (2007). Paisajes urbanos de la modernidad, Buenos Aires, Universidad Nacional de Quilmes.

González Stephan, Beatriz y Andermann, Jens (eds.) (2006). Galerias del progreso: museos, exposiciones y cultura visual en América Latina, Rosario, Beatriz Viterbo.

Magalhaes Júnior, R. (1978). A vida vertiginosa de João do Rio, Rio de Janeiro, Civilização Brasileira.

Molloy, Sylvia (2011). Poses de fin de siglo, Buenos Aires, Eterna Cadencia.

Montaldo, Graciela (2013). "Prólogo”, en Rubén Dario. Viajes de un cosmopolita extremo, Buenos Aires, FCE.

Ramos, Julio (1989). Desencuentros de la modernidad en América Latina. México, FCE.

Rodríguez Pérsico, Adriana (2008). Relatos de época: una cartografia de América Latina (1880-1920), Rosario, Beatriz Viterbo.

Romero, José Luis (2001). Latinoamérica, las ciudades y las ideas, Buenos Aires, Siglo XXI. 
Süssekind, Flora (1990). O Brasil não é longe daqui, Río de Janeiro, Companhia das Letras.

Terán, Oscar (1992). “El dispositivo hispanista”, en Luis Martínez Cuitiño y Elida Lois (eds). Actas III Tercer Congreso Argentino de Hispanistas España en América y América en España, Buenos Aires, Facultad de Filosofía y Letras, Instituto de Filología y Literatura Hispánica Dr. Amado Alonso, Tomo I, pp. 126-237.

Zanetti, Susana (2010). "España contemporánea de Rubén Darío entre la crónica y el ensayo", en Liliana Weinberg (comp.). Estrategias del pensar. I, México, Universidad Autónoma de México, pp. 65-92.

\section{Notas}

1 Graciela Montaldo define a Darío del siguiente modo: “...ser cosmopolita significaba ser versátil, ser una suerte de interlocutor absoluto, poder comunicarse con todos (con los iguales, con los diferentes, con los saberes particularizados y especializados pero también con la doxa) desde un espacio de enunciación que quería abarcarlo todo y que se constituía como lugar de poder. Darío fue un cosmopolita extremo" (Montaldo 2013: 12).

2 David Frisby plantea, en la "Introducción" a su libro Paisajes urbanos de la modernidad, que "son tantas las representaciones de nuestra experiencia de la modernidad que se vinculan a nuestra experiencia de la metrópoli, que la presentación y representación de la ciudad probablemente compartan las contradicciones de la modernidad" (Frisby 2007: 17). A partir de dicha afirmación, el autor propone diferentes observadores de la ciudad del período de entresiglos que, a su vez, establecen diversas distancias desde las cuales miran -y representan- la metrópoli.

3 João de Barros nació en Portugal en 1881. Ocupó diversos cargos públicos relacionados con la educación y las relaciones exteriores durante los primeros tiempos de la República, y fue un activo impulsor de los vínculos entre Portugal y Brasil. Además de la revista Atlántida, fundó y dirigió con otros intelectuales la revista Arte e vida.

$4 \mathrm{Al}$ respecto Susana Zanetti señala: "Ese espacio ficcional dariano, construido en el complejo borde en que se encuentran su intensa renovación y su revitalización de la tradición poética español autorizaba, a despecho de los voceros de esa celebración vacía de la antigua grandeza, su discurso, nuevo por entonces en Hispanoamérica, para promover desde su inconmovible cosmopolitismo y galomanía que se le achacaba, la unión con España sobre la base del respeto a la independencia y a las diferentes vías elegidas para la constitución de una literatura y una cultura propias" (Zanetti 2010: 78).

5 Cada una de estas crónicas ocupa las primeras dos columnas en la página 2 de la Gazeta de Notícias. Además del título que las engloba a todas ("Viajem a Buenos Aires"), cada nota lleva un título propio de acuerdo a los diferentes subtemas abordados por el autor durante su estadía en la capital argentina: "Buenos Aires", "Argentina-Brasil”, "Da calle Juncal ao Jockey Club”, “Tarde de domingo", “A partida”. Hasta el momento no han sido reeditadas. Por cuestiones de extensión, el presente trabajo sólo se ocupa de analizar la primera de ellas.

6 Raúl Antelo, en João do Rio. O Dândi e a especulação, remite al vínculo entre ambos escritores y a la influencia que el escritor guatemalteco ejerció sobre do Rio, especialmente atendiendo a las inquietudes sobre el espacio urbano compartidas entre El alma encantadora de París (de Enrique Gómez Carrillo, 1902) y A alma encantadora das ruas (de do Rio,1908). 